\title{
Coronavirus disease 2019 (COVID-19): a clinical update
}

\author{
Min Zhou ${ }^{1,2,3}$, Xinxin Zhang ${ }^{1,4}$, Jieming Qu $(\bowtie)^{1,2,3}$ \\ ${ }^{I}$ National Research Center for Translational Medicine, Ruijin Hospital Affiliated to Shanghai Jiao Tong University School of Medicine, \\ Shanghai 200025, China; ${ }^{2}$ Department of Respiratory and Critical Care Medicine, Ruijin Hospital Affiliated to Shanghai Jiao Tong \\ University School of Medicine, Shanghai 200025, China; ${ }^{3}$ Institute of Respiratory Diseases, Shanghai Jiao Tong University School of \\ Medicine, Shanghai 200025, China; ${ }^{4}$ Research Laboratory of Clinical Virology, Ruijin Hospital and Ruijin Hospital North Affiliated to \\ Shanghai Jiao Tong University School of Medicine, Shanghai 200025, China
}

(C) Higher Education Press and Springer-Verlag GmbH Germany, part of Springer Nature 2020

\begin{abstract}
Coronavirus disease 2019 (COVID-19) caused by severe acute respiratory syndrome coronavirus-2 (SARS-CoV-2) has posed a significant threat to global health. It caused a total of 80868 confirmed cases and 3101 deaths in Chinese mainland until March 8, 2020. This novel virus spread mainly through respiratory droplets and close contact. As disease progressed, a series of complications tend to develop, especially in critically ill patients. Pathological findings showed representative features of acute respiratory distress syndrome and involvement of multiple organs. Apart from supportive care, no specific treatment has been established for COVID-19. The efficacy of some promising antivirals, convalescent plasma transfusion, and tocilizumab needs to be investigated by ongoing clinical trials.
\end{abstract}

Keywords coronavirus disease 2019; epidemiology; pathology; radiology; clinical characteristics; treatment

\section{Introduction}

Currently, coronavirus disease 2019 (COVID-19) poses a significant threat to global health. World Health Organization (WHO) has declared this outbreak as a "public health emergency of international concern" on January 31, 2020. Within the first two months of the outbreak, the epidemic spread rapidly around the country and the world. As of March 8, 2020, a total of 80868 confirmed cases and 3101 deaths had been reported in Chinese mainland by National Health Commission of China, and 90 other countries are affected. COVID-19 as an emerging disease, has unique biological characteristics, clinical symptoms, and imaging manifestations, though considerable progress has been made on the clinical management. This article will summarize the epidemiological, etiological, clinical, pathological, and radiological characteristics of COVID19 and review the latest advancements in the treatment.

Received March 9, 2020; accepted March 11, 2020

Correspondence: Jieming Qu, jmqu0906@163.com

\section{The epidemiology of COVID-19}

Epidemic curves reflect that this epidemic may be a mixed outbreak pattern, with early cases suggestive of a continuous common source, potentially at Huanan Seafood Wholesale Market (HSWM), and later cases suggestive of a propagated source as the virus began to be transmitted from person to person [1]. A retrospective analysis on the first 425 patients with confirmed COVID-19 showed that during the early stages of this outbreak, the basic reproduction number $\mathrm{R}_{0}$ was estimated to be 2.2 [2]. Considering the strict prevention and control measures implemented by the Chinese government, a phase-adjusted estimation of epidemic dynamics assumed that the effective reproduction number $\mathrm{R}_{0}$ was 3.1 at the early phase of the epidemic, and could be gradually decreased [3].

Of the first 99 laboratory-confirmed patients, 49 (49\%) had been exposed to HSWM, which was reported to be the possible initial source of severe acute respiratory syndrome coronavirus-2 (SARS-CoV-2) [4]. A Shenzhen family cluster without exposure history to Wuhan markets or wild animals also proved the possibility of person-to-person transmission [5]. Another family cluster of patients provided evidence that asymptomatic carriers may also be potential sources of SARS-CoV-2 infection [6]. 
SARS-CoV-2 spread mainly through respiratory droplets or close contact. While in the later stage of infection, the virus is also detectable in anal swabs, suggesting the possibility of oral-fecal route transmission [7]. Significant environmental contamination by patients carrying SARSCoV-2 through respiratory droplets and fecal shedding suggests that the environment serves as a potential medium of transmission and supports the requirement for strict adherence to environmental and hand hygiene [8]. Currently, there is no clear evidence of infection caused by vertical transmission or aerosol transmission.

\section{Virological characteristics of SARS-CoV-2}

SARS-CoV-2 is the causative pathogen of COVID-19, identified as the seventh type of coronavirus to infect humans [9]. Six other kinds of coronaviruses are known to cause human disease, including severe acute respiratory syndrome coronavirus (SARS-CoV) and Middle East respiratory syndrome coronavirus (MERS-CoV) with high mortality rate [10]. According to the genome characteristics, coronavirus is separated into four genera: $\alpha-\mathrm{CoV}, \beta-\mathrm{CoV}, \gamma-\mathrm{CoV}$, and $\delta$-CoV [10]. Deep sequencing revealed that this novel coronavirus isolated from lower respiratory tract samples of patient with COVID-19 belongs to $\beta-\mathrm{CoV}[9]$.

Coronavirus has the appearance of crown under electron microscopy. They are enveloped viruses with a singlestrand, positive-sense RNA genome, which is the largest known genome for an RNA virus [11]. All coronaviruses share the same genome organization and expression pattern, with two large overlapping reading frames (ORF1a/b) which encode 16 nonstructural proteins, followed by ORFS for four major structural proteins: spike (S), envelope (E), membrane (M), and nucleocapsid (N) [11]. Spike protein plays an essential role in binding to receptors and is critical for determining host tropism and transmission capacity. It is functionally divided into S1 domain and S2 domain, responsible for receptor binding and cell membrane fusion respectively. The receptor binding domain (RBD) of $\beta-\mathrm{CoV}$ is commonly located in the C-terminal domain of S1 [12]. A team analyzed the cryogenic electron microscopy (Cryo-EM) structure of the SARS-CoV-2 spike protein and found that it has 10 to 20fold higher binding affinity to human angiotensin-converting enzyme 2 (ACE2) than SARS-CoV does [13].

Phylogenetic analysis of the evolution history showed that SARS-CoV-2 shared a closer sequence homology toward the genomes of SARS-CoV than to that of MERS$\mathrm{CoV}$ [14]. SARS-CoV-2 is highly similar to a bat coronavirus RaTG13, with an overall genome sequence identity of $96.2 \%$ [15], indicating that bat, which was discovered to be the natural reservoir host of various
SARS-related coronaviruses [16], may also be the original host of SARS-CoV-2. The intermediate host in the process of transmission remains uncertain.

\section{Clinical characteristics}

\section{Clinical manifestation}

COVID-19 has an incubation period of 1-14 days, mostly ranging from 3 to 7 days [17]. The most common symptoms in mild to moderate patients are fever, fatigue, and dry cough, followed by other symptoms including headache, nasal congestion, sore throat, myalgia, and arthralgia [4,18-20]. A minority of patients had gastrointestinal symptoms, such as nausea, vomiting, and diarrhea, especially in children. In the study of 1099 COVID-19 patients, $43.8 \%$ cases presented fever at onset of illness and the percentage further increased to $88.7 \%$ during following hospitalization [21]. Notably, fever may occasionally be absent from elderly persons or immunocompromised ones.

A part of patients may progress to shortness of breath, usually in the second week of the illness, and might be accompanied by or progress to hypoxemia [22,23]. For patients presenting tachypnea, chest indrawing, or inability to feed or drink, severe pneumonia should be considered. In $10 \%$ to $20 \%$ of severe patients, the respiratory injury will inevitably develop into acute respiratory distress syndrome (ARDS) during 8-14 days of the illness, defined as partial pressure of oxygen $\left(\mathrm{PaO}_{2}\right)$ to fraction of inspired oxygen $\left(\mathrm{FiO}_{2}\right)$ ratio lower than $300 \mathrm{mmHg}$, as well as resultant non-cardiogenic pulmonary edema and mechanical ventilation $[21,22,24]$. ARDS, as the main cause of respiratory failure, is associated with high morbidity and mortality. Risk factors for developing into severe to critical cases include advanced age, underlying comorbidities such as hypertension, diabetes, cardiovascular disease, and cerebrovascular disease $[20,22,23]$.

As disease progresses, a series of complications tend to occur, especially in critically ill patients admitted to ICU, including shock, sepsis, acute cardiac injury, acute kidney injury, and even multi-organ dysfunction [20,21,23]. Patients may manifest altered mental status, low oxygen saturation, reduced urine output, weak pulse, cold extremities, low blood pressure, and mottled skin. Besides, patients with acute cardiac injury would present tachycardia or bradycardia. Critically ill ones may also suffer acidosis and increased lactate [20-22]. Current studies reported the peak value of temperature in non-survivors of COVID-19 was significantly higher than that in survivals during hospitalization [20,21]. Thus, patients presenting hyperthermia and chill should exclude the possibilities of co-infection with bacteria or other pathogens. Attentions 
should be paid to prevent hospital-acquired pneumonia (HAP) in critical cases and ventilator-associated pneumonia (VAP) in those receiving mechanical ventilation. Coagulopathy and thrombocytopenia are also common complications for COVID-19 infection, which increase the risk of hemorrhage and thrombosis. Mottled skin, petechial or purpuric rash, appearance of black stool or hematuresis could be found in some cases. Patients with the syndrome of persistent hypoxemia, chest pain, pre-syncope or syncope, and hemoptysis should be suspected of having pulmonary thromboembolism (PTE) [25]. The manifestation of limb pain, swelling, erythema, and dilated superficial veins should be suspected of deep vein thrombosis (DVT). Nearly $20 \%$ of patients had abnormal coagulation function, and most of severe and critical patients presented coagulation disorders and had the tendency to develop into disseminated intravascular coagulation (DIC) $[4,22,23]$.

\section{Radiological and pathological features}

In the early stage of infection, the involved lung lobe presented obvious alveolar edema, proteinaceous exudates, and reactive pneumocyte hyperplasia, accompanied by mild inflammatory infiltration [26]. On gross examination, the whole lung showed bronzing surface and diffuse congestive appearance, with partly hemorrhagic necrosis, as same as the cut surfaces. On histological examination, the typical manifestations were extensive proteinaceous and serous exudation in the alveolar, hyaline membrane formation, and inflammatory infiltration with multinucleated syncytial cells. Type II alveolar epithelial cells showed extensive hyperplasia, and some presented necrosis and desquamation. Viral inclusions could be identified in epithelium and macrophage. Besides, alveolar septal vessels manifested congestion with alveolar edema. The infiltration of monocytes and lymphocytes in alveolar cavity and microthrombosis were prominent. Some parts showed alveolar exudate organization and pulmonary interstitial fibrosis. With a fraction of desquamation of mucosal epithelium, bronchi were covered by mucus even mucus plug $[17,27,28]$.

In addition, other organs also suffered pathological damage to some extent [17]. The atrophic spleen showed significantly reduced lymphocytes, focal hemorrhage and necrosis, and macrophage hyperplasia. With degeneration and necrosis of cardiomyocytes, a small number of monocytes, lymphocytes, and/or neutrophils were infiltrated in the myocardial interstitium. Protein exudation was seen in renal glomerulus and within hyaline cast, and renal tubular epithelium degenerated and desquamated. Besides, hepatocytes degeneration, necrosis, and inflammatory infiltration also occurred. The brain presented congestion, edema, and degeneration of some neurons. Meanwhile, microthrombosis could be found in multiple organs.
Radiological images play an important role in the diagnosis and providing guidance for treatment. Guan et al. found that $86.2 \%$ of patients manifested abnormalities in chest CT images, of whom more than $75 \%$ had bilateral lung involvement, mainly with peripheral and diffused distribution [21]. Patients of different severity presented significant different lesions on chest CT (Fig. 1). Mild patients manifested unilateral and focal ground-glass opacity (GGO) which gradually develops to bilateral or multilobular lesions. As the disease progressed further, GGOs evolved to consolidation lesions, presenting mixpattern or pure consolidation, with the latter being more common in critically ill patients admitted to ICU $[4,22,29]$. Consistent with the interstitial involvement in viral pneumonia, Zhao et al. suggested that $48.5 \%$ of CT images manifested reticular patterns, and $28.7 \%$ presented interlobular septal thickening [30]. Unlike influenza pneumonia, which usually exhibited unilateral GGO and significant solid nodules, only $6 \%$ of COVID-19 patients had solid nodules [29,31,32]. Moreover, other lesions included adjacent pleura thickening, vascular enlargement, bronchial wall thickening, traction bronchiectasis, air bronchogram, pericardial effusion, etc. [29,30,33].

Follow-up of CT scan could help to monitor disease changes and evaluate therapeutic effects [29]. Some dynamic images fluctuate repeatedly, and showed coexistence of absorption of primary lesions and emergence of new ones. During disease deterioration, increased number of or enlarged lesions could be observed in radiological imaging, and part of them even developed into a "white lung" with diffusely involved lung [34].

\section{Laboratory examinations}

A majority of COVID-19 patients showed normal leucocyte count, and nearly one third had leucopenia $[18,21]$. Lymphocytopenia, as one of the most typical laboratory abnormalities, was present in $83.2 \%$ of patients, with an even higher proportion in severe ones [21,23]. In addition, previous studies also revealed that increased Ddimer level and prolonged prothrombin time were also common features of COVID-19, especially for severe patients [21-23]. Meanwhile, SARS-CoV-2 might damage liver and myocardium to some extent, showing elevated levels of aminotransferase, creatine kinase, and myoglobin with diverse degrees, as well as increased troponin in critical patients [4,20,22]. A few patients had renal dysfunction, presenting increased serum creatinine or blood urea nitrogen [4].

As for infection-related serum biomarkers, our studies have reported that most of patients had increased concentration of C-reactive protein, interleukin-6 (IL-6), and erythrocyte sedimentation rate [4]. Likewise, Huang et al. observed similar phenomenon and proposed that ICU 


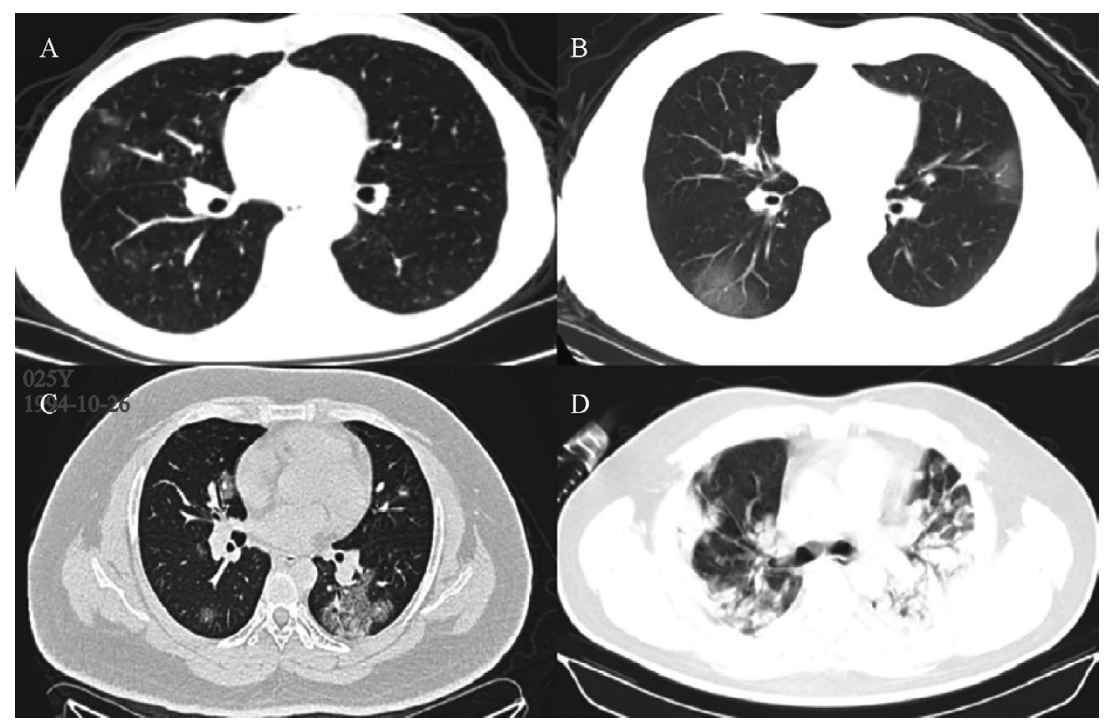

Fig. 1 Chest CT of COVID-19 patients with different severity. (A) A 57-year-old man with mild COVID-19 showed unilateral and slight GGO. (B) A 52-year-old male patient classified into moderate type exhibited multifocal and bilateral GGO with sub-pleural distribution. (C) In a 26-year-old man with severe COVID-19, bilateral and multifocal lesions were observed with a combination of pure GGO, mixed GGO, and consolidation. (D) In a 50-year-old critically ill women, chest CT showed bilateral massive shadows of high density and GGO, accompanied by air bronchogram sign.

patients might suffer severe cytokine storms, with a overproduction of IL-7, IL-10, GCSF, IP10, MCP1, MIP1A, and TNF- $\alpha$, etc. [22]. Multi-drug resistant Acinetobacter baumannii and Klebsiella pneumoniae have been isolated in COVID-19 patients [4,20]. Other identified microorganisms included Pseudomonas aeruginosa, Aspergillus flavus, Aspergillus fumigatus, Candida albicans, and Candida glabrata $[4,20]$.

\section{Diagnostic testing for COVID-19}

Laboratory confirmed COVID-19 patients had positive results on real-time reverse transcriptase polymerase chain reaction (RT-PCR) of nasal and pharyngeal swab, sputum, blood, faeces, and urine specimens [22]. The collected clinical specimens need to be transported to designated laboratories promptly, and extracted for RNA correctly, followed by RT-PCR detection with primers and probes of appropriate sequences [22]. The value of cycle threshold (Ct) was the criterion to determine the detection result, with less than 37 being defined as negative, above 40 as positive and a medium load (37-40) calling for confirmation by retesting [2].

The detection of SARS-CoV-2 specific IgM and IgG antibodies can also be used for diagnosis [17]. COVID-19 infection could be determined with one of the following criteria: positive specific IgM, the transformation of specific IgG from negative to positive, a 4-fold increase in $\operatorname{IgG}$ titer during recovery period compared with the result of acute phase. Although antibody detection was simple, rapid, and inexpensive, it is still not widely used due to inherent limitations, for example, false-negativity resulted from the existence of window period, noncomparable sensitivity and specificity with PT-PCR, absence of exclusion criteria making it a diagnosis tool only.

\section{Treatment}

\section{Antiviral agents}

These is no specific antiviral treatment which has been proven to be effective for COVID-19. Combinations of over three antivirals are not suggested. Current treatment options are mainly based on previous experience showing clinical benefits in treating influenza, Ebola, MERS, SARS, and other viral infections. It is reported that most of COVID-19 patients received antiviral therapy in China $[4,18,22]$, and here we will introduce some commonly used drugs.

Ribavirin is representative of nucleoside analogs. The combination of ribavirin and recombinant interferon, a broad spectrum antiviral agent, showed augmentation effect in inhibiting MERS-CoV replication and reduced doses of both ribavirin and interferon [35]. However, most of clinical experiences in MERS patients come from limited case reports and observational studies, making the 
quality of evidence for ribavirin and interferon treatment efficacy very low [36]. It is recommended to administer ribavirin by intravenous infusion in combination with inhaled interferon- $\alpha$ or oral lopinavir/ritonavir in the 5 th version guideline on COVID-19 diagnosis and treatment issued by Chinese National Health Commission [17]. Notably, ribavirin is not suggested by military medical team coming to Hubei [37] and interferon- $\alpha$ inhalation is worried to increase the risk of virus-containing aerosol production and airway stimulation.

Lopinavir/ritonavir is a combination of a protease inhibitor and a booster used for the treatment of human immunodeficiency virus (HIV) infection. Currently, randomized controlled trials for the efficacy of a combination of lopinavir/ritonavir with interferon- $\alpha$ in mild to moderate patients (ChiCTR2000029387) and severe to critical patients with COVID-19 (ChiCTR2000029308) are in progress.

Remdesivir, a novel nucleotide analog RNA polymerase inhibitor, is considered as the most promising antiviral drug for the treatment of COVID-19. It showed broad spectrum antiviral activities, from inhibition of human and zoonotic coronavirus (including SARS-CoV-2 [38] as well Ebola virus) in vitro, to prophylactic and therapeutic effects in animal model of MERS-CoV and SARS-CoV infection $[39,40]$. The first COVID-19 patient identified in the United States was given remdesivir without obvious adverse reactions. Two trials on efficacy of remdesivir have been launched in China among mild to moderate patients (NCT04252664) and severe to critical patients (NCT04257656) infected with SARS-CoV-2.

Neuraminidase inhibitors (NAIs), such as oral oseltamivir and intravenous peramivir, showed substantial clinical improvement in treating influenza patients [41]. Oseltamivir was widely used for suspected and confirmed COVID19 patients in China [23], however, there is no exact evidence that supports its application.

A research team from Zhejiang University reported that abidol has the potential to inhibit SARS-CoV-2, which was previously used for influenza. There is a multicenter, randomized, and controlled trial (ChiCTR2000029573) to evaluate the efficacy of abidol and lopinavir/litonavir, either alone or in combination with a new type of interferon, Novaferon.

\section{Corticosteroids}

According to current WHO interim guidance on COVID19 management [24], corticosteroids were not recommended as routine therapy unless indicated for another reason, because possible harms and higher risk of mortality attributed to corticosteroids therapy have been identified by studies on other coronaviruses and influenza.

An epidemiological study conducted in Wuhan observed a larger percentage of patients receiving corticosteroids in
ICU groups when compared with non-ICU groups (6 $(46 \%)$ vs. $3(11 \%) ; P=0.013)$, while we still cannot determine the effects of corticosteroids due to the limited sample size [22]. According to the latest guidelines issued by National Health Commission of China (version 7) [17] and the interim guidance of WHO [24], when SARS-CoV2 infection is suspected, corticosteroids should be recommended to use with caution. New Coronavirus Infection Diagnosis and Treatment Scheme (Trial Version) published by Military Support Hubei Medical Team also put forward that for mild to moderate COVID-19 patients, corticosteroids should not be given principally and high-dose corticosteroid pulse therapy was not recommended. Only patients presenting ongoing deterioration in oxygenation index, or rapid progression of radiological findings, or excessive activation of immune responses, will be considered to use short-term corticosteroid therapy within 10 days of illness onset. Seven designated hospitals in Zhejiang Province gave patients corticosteroids when they showed increased resting respiratory rate $(>30$ breaths/minute), drop in oxygen saturation $(<93 \%)$ on room air, or multi-lobular progression $(>50 \%)$ on imaging within $48 \mathrm{~h}$ [18]. Timely and appropriate use of corticosteroids combined with ventilator support should be considered for severe patients to prevent progression to ARDS [27].

The pharmacologic use of corticosteroids in COVID-19 treatment should vary with severity [17,37]. For severe cases, it is suggested to start at a dose of 40 to $80 \mathrm{mg} /$ day methylprednisolone and slowly taper over 7 to 10 days, and some suggested for a shorter period of 3 to 5 days. For critically ill cases, a starting dose of 80 to $160 \mathrm{mg}$ /day methylprednisolone, following a slow withdrawal within 7 to 10 days is considered.

\section{Antimicrobial therapy}

It is widely recognized that many patients, especially critically ill patients were susceptible to secondary infections. Patients receiving corticosteroids had increased risks of developing HAP due to the immunosuppression effects, and those who received mechanical ventilation were susceptible to VAP. The latest guidelines issued by National Health Commission of China for the diagnosis and treatment of COVID-19 infection (version 7) [17] advise against inappropriate and unnecessary use of antimicrobial therapy, especially combination of broadspectrum antibiotics. If the sputum or blood specimens showed a clear evidence of etiology or the PCT levels increased, administration of antimicrobial agents should be considered.

As shown in a study of 99 patients with COVID-19, Acinetobacter baumannii, Klebsiella pneumoniae, and Aspergillus flavus were simultaneously cultured in one patient. Meanwhile, one case of fungal infection was 
attributed to Candida glabrata and three cases of fungal infection were caused by Candida albicans [4].

When selecting antimicrobial agents for initial empiric treatment, in addition to the local epidemiological data of HAP/VAP pathogens, imaging features of pulmonary lesions should also be taken into account [42].

As for fungal infections, voriconazole is recommended for the treatment of Aspergillus infections, while fluconazole is more suitable for Candida spp. infections. When patients are suspected with Pneumocystis pneumonia, sulfamethoxazole and caspofungin should be promptly administrated [42].

\section{Anticoagulant}

In clinical practice, nearly $20 \%$ of patients with COVID-19 are found to have abnormal coagulation function, and almost all severely and critically ill patients presented coagulation disorders $[4,22,23]$. In view of no relevant experience for reference, anticoagulation should be given with great caution in patients with DIC though microthrombosis was observed in lung, liver, and other organs by autopsy. When patients exhibit a bleeding tendency or when surgical treatment is needed, platelet transfusion or administration of fresh-frozen plasma is recommended to correct coagulopathies analogs [43].

Low molecular weight heparin (LMWH) can be used for drug prevention. As for subjects with clinical manifestations, clinicians need to be alert to the occurrence of PTE, initiate the diagnostic procedures, and develop corresponding treatment strategies based on risk stratification. Considering the risk of disease transmission and the false positive results caused by the presence of lung lesions, the diagnosis of PTE by pulmonary ventilation-perfusion imaging is not recommended.

If the critically ill patients cannot take examination due to specific conditions and the infectivity of COVID-19, it is recommended to perform anticoagulant therapy for patients without contraindications. If the condition is lifethreatening and bedside echocardiography indicates new onset of right ventricular volume overload or pulmonary hypertension, thrombolytic therapy or other cardiopulmonary support treatments, such as extracorporeal membrane oxygenation (ECMO) can be initiated with the patient's full informed consent.

\section{Oxygen therapy}

For mild to moderate patients with hypoxemia, nasal catheters and masks and even high-flow nasal cannula oxygen therapy (HFNC) are advised. While for severe and critical patients with respiratory distress, HFNC, noninvasive mechanical ventilation (NIV) or invasive mechanical ventilation, and even ECMO should be considered.
HFNC

HFNC can provide accurate oxygen concentration and a certain positive airway pressure to promote alveolar expansion to improve oxygenation and respiratory distress [44]. However, according to expert consensus on the use of HFNC for COVID-19, patients with cardiac arrest, weak spontaneous breathing, $\mathrm{PaO}_{2} / \mathrm{FiO}_{2}<100 \mathrm{mmHg}$, $\mathrm{PaCO}_{2}>45 \mathrm{mmHg}$ and $\mathrm{pH}<7.25$ and upper airway obstruction are contraindicated.

\section{NIV or invasive mechanical ventilation}

For severe patients with respiratory distress or hypoxemia that cannot be alleviated after standard oxygen therapy, NIV can also be considered with close surveillance $[21,23]$. Dangers et al. considered that changes in dyspnea could be used as a variable to predict the failure of noninvasive ventilation [45]. If the patient continuously deteriorates or the respiratory rate cannot be improved after a short time (about 1-2 h), timely tracheal intubation and invasive ventilation are required [46]. Notably, patients with hemodynamic instability, multiple organ failure or abnormal mental status should not receive noninvasive ventilation.

Lung protection ventilation strategies (small tidal volume, limited plateau pressure, and permissive hypercapnia) are suggested to be adopted in invasive mechanical ventilation to reduce ventilator-related lung injury [47]. Compared with NIV, invasive mechanical ventilation can more effectively improve the pulmonary ventilation function and respiratory mechanics of patients with acute respiratory failure. It can effectively increase the $\mathrm{SaO}_{2}$ level and is more conducive to lower the plasma BNP level [48]. However, invasive mechanical ventilation requires tracheotomy, or oral/nasal tracheal intubation to establish an artificial airway, which is very likely to cause damage to patients, such as mediastinal emphysema, ventilatorrelated lung injury, and other related complications, such as reduced swallowing function, gastresophageal reflux, infections, etc. What's more, invasive mechanical ventilation also increases the risk of secondary infections transmitted by aerosol particles [49].

\section{Continuous renal replacement therapy (CRRT)}

For critical patients, CRRT can support organ function, reduce cytokine storms and maintain internal environment stability [50]. Three clinical studies showed that the incidence of AKI in patients with COVID-19 was $3 \%$ to $7 \%$, and $7 \%$ to $9.0 \%$ were treated with CRRT. In ICU, the rate of CRRT application was $5.6 \%$ to $23.0 \%$ and reached as high as $66.7 \%$ to $100 \%$ in patients with AKI $[4,23,51]$. CRRT is recommended for patients who exhibit AKI 
indications (hyperkalemia, acidosis, pulmonary edema, severe sodium ion disorders) or patients with CKD who have not undergone hemodialysis. During septic shock, CRRT can effectively remove inflammatory mediators and significantly improve hemodynamics. When ARDS appears in combination with multiple organ dysfunction syndrome (MODS), early CRRT is recommended [52]. CRRT combined with the treatment of ECMO may remove cytokines, reduce the activity of macrophages and monocytes, and better preserve lung parenchyma.

\section{Convalescent plasma therapy for COVID-19}

Some studies reported that early convalescent plasma treatment for influenza and SARS-CoV infection is associated with decreased viral load and reduction in mortality [53], however, the studies were heterogeneous and of low quality. The WHO deemed convalescent plasma transfusion as the most promising therapy for MERS-CoV infection, while the efficacy remained inconclusive, with a lack of adequate clinical trials [53-55]. Since the virological and clinical characteristics among SARS, MERS, and COVID-19 were comparable [56], convalescent plasma could have immunotherapeutic potential in COVID-19 treatment and further investigations are needed to prove its safety and efficacy.

One possible explanation for the efficacy of convalescent plasma therapy is that the neutralizing antibodies from convalescent plasma might suppress viremia [57], so understanding the antibody response during the course of SARS-CoV-2 infection could provide strong empirical support for the application of convalescent plasma therapy. A study reported that on day 5 after treatment, an increase of viral antibodies can be seen in nearly all patients, IgM positive rate increased to $81 \%$, whereas IgG positive rate increased to $100 \%$, which was considered as a transition from earlier to later period of infection [7]. Preliminary study has showed that patients who have recovered from COVID-19 with a high neutralizing antibody titer and could provide a valuable source of the convalescent plasma.

Plasma transfusion may cause adverse effects, so convalescent plasma therapy is recommended as a last resort to improve the survival rate of severe patients with COVID-19. The optimal dose and treatment time point, as well as the therapeutic indications of convalescent blood products in COVID-19 remain uncertain, which need to be further investigated in randomized clinical studies.

\section{Tocilizumab}

Tocilizumab is a humanized IgG1 $\kappa$ monoclonal antibody which can specifically bind soluble or membrane-type IL-6 receptors (Sil-6R and Mil-6R), and has been widely used in the treatment of autoimmune diseases such as rheumatoid arthritis [58], adult-onset Still's disease [59], and large vessel vasculitis [60]. For COVID-19 infection, clinical studies have shown that serum levels of inflammatory mediators in severe patients are significantly higher than those in common patients [22]. Excessive immune responses can trigger cytokine storms and cause damage to multiple target organs. Recent guidelines also point that a progressive rise in IL-6 may be a clinical warning indicator for the deterioration of COVID-19. A domestic research team found that tocilizumab can block the signaling pathways of two key inflammatory factors, IL6 and GM-CSF, and reduce the inflammatory response. A multicenter, randomized, controlled clinical study has been coducted to evaluate the efficacy and safety of tocilizumab in the treatment of moderate patients at high risk to develop into severe and critical patients (registration number: ChiCTR2000029765). For patients with elevated IL-6 levels, the efficacy of tocilizumab can be expected.

\section{Conclusions}

In this review, we gave an overview of epidemiological, etiological, clinical, pathological, and imaging characteristics of COVID-19 and introduced the latest advancements in the treatment. This novel virus spread mainly through respiratory droplets and close personal contact. A series of complications tend to develop during disease progression, especially in critically ill patients. Pathological studies of autopsy showed typical presentations of acute respiratory distress syndrome and involvement of multiple organs. Apart from supportive care, no specific treatment has been established for COVID-19. The efficacy of some promising antivirals, convalescent plasma transfusion, and tocilizumab needs to be further validated by ongoing clinical trials.

\section{Acknowledgements}

This work was funded in part by a grant from innovative research team of high-level local universities in Shanghai.

\section{Compliance with ethic guidelines}

Min Zhou, Xinxin Zhang, and Jieming Qu declare that they have no conflict of interest. This manuscript is a review article that does not involve a research protocol requiring approval by the relevant institutional review board or ethics committee.

\section{References}

1. Wu Z, McGoogan JM. Characteristics of and important lessons from the coronavirus disease 2019 (COVID-19) outbreak in China: summary of a report of 72314 cases from the Chinese Center for Disease Control and Prevention. JAMA 2020 Feb 24. [Epub ahead 
of print] doi: 10.1001/jama.2020.2648

2. Li Q, Guan X, Wu P, Wang X, Zhou L, Tong Y, Ren R, Leung KSM, Lau EHY, Wong JY, Xing X, Xiang N, Wu Y, Li C, Chen Q, Li D, Liu T, Zhao J, Liu M, Tu W, Chen C, Jin L, Yang R, Wang Q, Zhou S, Wang R, Liu H, Luo Y, Liu Y, Shao G, Li H, Tao Z, Yang Y, Deng Z, Liu B, Ma Z, Zhang Y, Shi G, Lam TTY, Wu JTK, Gao GF, Cowling BJ, Yang B, Leung GM, Feng Z. Early transmission dynamics in Wuhan, China, of novel coronavirus-infected pneumonia. N Engl J Med 2020 Jan 29. [Epub ahead of print] doi: 10.1056/ NEJMoa2001316

3. Wang H, Wang Z, Dong Y, Chang R, Xu C, Yu X, Zhang S, Tsamlag L, Shang M, Huang J, Wang Y, Xu G, Shen T, Zhang X, Cai Y. Phase-adjusted estimation of the number of coronavirus disease 2019 cases in Wuhan, China. Cell Discov 2020; 6(1): 10

4. Chen N, Zhou M, Dong X, Qu J, Gong F, Han Y, Qiu Y, Wang J, Liu Y, Wei Y, Xia J, Yu T, Zhang X, Zhang L. Epidemiological and clinical characteristics of 99 cases of 2019 novel coronavirus pneumonia in Wuhan, China: a descriptive study. Lancet 2020; 395 (10223): 507-513

5. Chan JF, Yuan S, Kok KH, To KK, Chu H, Yang J, Xing F, Liu J, Yip CC, Poon RW, Tsoi HW, Lo SK, Chan KH, Poon VK, Chan WM, Ip JD, Cai JP, Cheng VC, Chen H, Hui CK, Yuen KY. A familial cluster of pneumonia associated with the 2019 novel coronavirus indicating person-to-person transmission: a study of a family cluster. Lancet 2020; 395(10223): 514-523

6. Huang R, Xia J, Chen Y, Shan C, Wu C. A family cluster of SARSCoV-2 infection involving 11 patients in Nanjing, China. Lancet Infect Dis 2020 Feb 28. [Epub ahead of print] doi: 10.1016/S14733099(20)30147-X

7. Zhang W, Du RH, Li B, Zheng XS, Yang XL, Hu B, Wang YY, Xiao GF, Yan B, Shi ZL, Zhou P. Molecular and serological investigation of 2019-nCoV infected patients: implication of multiple shedding routes. Emerg Microbes Infect 2020; 9(1): 386389

8. Ong SWX, Tan YK, Chia PY, Lee TH, Ng OT, Wong MSY, Marimuthu K. Air, surface environmental, and personal protective equipment contamination by severe acute respiratory syndrome coronavirus 2 (SARS-CoV-2) from a symptomatic patient. JAMA 2020 Mar 4. [Epub ahead of print] doi: 10.1001/jama.2020.3227

9. Zhu N, Zhang D, Wang W, Li X, Yang B, Song J, Zhao X, Huang B, Shi W, Lu R, Niu P, Zhan F, Ma X, Wang D, Xu W, Wu G, Gao GF, Tan W; China Novel Coronavirus Investigating and Research Team. A novel coronavirus from patients with pneumonia in China, 2019. N Engl J Med 2020; 382(8): 727-733

10. Su S, Wong G, Shi W, Liu J, Lai ACK, Zhou J, Liu W, Bi Y, Gao GF. Epidemiology, genetic recombination, and pathogenesis of coronaviruses. Trends Microbiol 2016; 24(6): 490-502

11. Forni D, Cagliani R, Clerici M, Sironi M. Molecular evolution of human coronavirus genomes. Trends Microbiol 2017; 25(1): 35-48

12. Lu R, Zhao X, Li J, Niu P, Yang B, Wu H, Wang W, Song H, Huang B, Zhu N, Bi Y, Ma X, Zhan F, Wang L, Hu T, Zhou H, Hu Z, Zhou W, Zhao L, Chen J, Meng Y, Wang J, Lin Y, Yuan J, Xie Z, Ma J, Liu WJ, Wang D, Xu W, Holmes EC, Gao GF, Wu G, Chen W, Shi W, Tan W. Genomic characterisation and epidemiology of 2019 novel coronavirus: implications for virus origins and receptor binding. Lancet 2020; 395(10224): 565-574

13. Wrapp D, Wang N, Corbett KS, Goldsmith JA, Hsieh CL, Abiona O, Graham BS, McLellan JS. Cryo-EM structure of the 2019-nCoV spike in the prefusion conformation. Science $2020 \mathrm{Feb} 19$. [Epub ahead of print] doi: 10.1126/science.abb2507

14. Xu X, Chen P, Wang J, Feng J, Zhou H, Li X, Zhong W, Hao P. Evolution of the novel coronavirus from the ongoing Wuhan outbreak and modeling of its spike protein for risk of human transmission. Sci China Life Sci 2020; 63(3): 457-460

15. Zhou P, Yang XL, Wang XG, Hu B, Zhang L, Zhang W, Si HR, Zhu Y, Li B, Huang CL, Chen HD, Chen J, Luo Y, Guo H, Jiang RD, Liu MQ, Chen Y, Shen XR, Wang X, Zheng XS, Zhao K, Chen QJ, Deng F, Liu LL, Yan B, Zhan FX, Wang YY, Xiao GF, Shi ZL. A pneumonia outbreak associated with a new coronavirus of probable bat origin. Nature 2020; 579(7798): 270-273

16. de Wit E, van Doremalen N, Falzarano D, Munster VJ. SARS and MERS: recent insights into emerging coronaviruses. Nat Rev Microbiol 2016; 14(8): 523-534

17. National Health Commission of the People's Republic of China. Guideline for the diagnosis and treatment of COVID-19 infections (version 1-7). 2020. http://www.nhc.gov.cn/yzygj/zcwj2/ new_zcwj.shtml (accessed March 9, 2020)

18. Xu XW, Wu XX, Jiang XG, Xu KJ, Ying LJ, Ma CL, Li SB, Wang HY, Zhang S, Gao HN, Sheng JF, Cai HL, Qiu YQ, Li LJ. Clinical findings in a group of patients infected with the 2019 novel coronavirus (SARS-Cov-2) outside of Wuhan, China: retrospective case series. BMJ 2020; 368: m606

19. Zhang JJ, Dong X, Cao YY, Yuan YD, Yang YB, Yan YQ, Akdis CA, Gao YD. Clinical characteristics of 140 patients infected with SARS-CoV-2 in Wuhan, China. Allergy 2020 Feb 19. [Epub ahead of print] doi: 10.1111/all.14238

20. Yang X, Yu Y, Xu J, Shu H, Xia J, Liu H, Wu Y, Zhang L, Yu Z, Fang M, Yu T, Wang Y, Pan S, Zou X, Yuan S, Shang Y. Clinical course and outcomes of critically ill patients with SARS-CoV-2 pneumonia in Wuhan, China: a single-centered, retrospective, observational study. Lancet Respir Med 2020 Feb 24. [Epub ahead of print] doi: 10.1016/S2213-2600(20)30079-5

21. Guan WJ, Ni ZY, Hu Y, Liang WH, Ou CQ, He JX, Liu L, Shan H, Lei CL, Hui DSC, Du B, Li LJ, Zeng G, Yuen KY, Chen RC, Tang CL, Wang T, Chen PY, Xiang J, Li SY, Wang JL, Liang ZJ, Peng YX, Wei L, Liu Y, Hu YH, Peng P, Wang JM, Liu JY, Chen Z, Li G, Zheng ZJ, Qiu SQ, Luo J, Ye CJ, Zhu SY, Zhong NS; China Medical Treatment Expert Group for COVID-19. Clinical characteristics of coronavirus disease 2019 in China. N Engl J Med 2020 Feb 28. [Epub ahead of print] doi: 10.1056/ NEJMoa2002032

22. Huang C, Wang Y, Li X, Ren L, Zhao J, Hu Y, Zhang L, Fan G, Xu J, Gu X, Cheng Z, Yu T, Xia J, Wei Y, Wu W, Xie X, Yin W, Li H, Liu M, Xiao Y, Gao H, Guo L, Xie J, Wang G, Jiang R, Gao Z, Jin Q, Wang J, Cao B. Clinical features of patients infected with 2019 novel coronavirus in Wuhan, China. Lancet 2020; 395(10223): 497506

23. Wang D, Hu B, Hu C, Zhu F, Liu X, Zhang J, Wang B, Xiang H, Cheng Z, Xiong Y, Zhao Y, Li Y, Wang X, Peng Z. Clinical characteristics of 138 hospitalized patients with 2019 novel coronavirus-infected pneumonia in Wuhan, China. JAMA 2020 Feb 7. [Epub ahead of print] doi: 10.1001/jama.2020.1585

24. WHO. Clinical management of severe acute respiratory infection when novel coronavirus (nCoV) infection is suspected: interim guidance. 2020. https://www.who.int/publications-detail/clinicalmanagement-of-severe-acute-respiratory-infection-when-novel-cor- 
onavirus-(ncov)-infection-is-suspected (accessed March 9, 2020)

25. Konstantinides SV, Meyer G, Becattini C, Bueno H, Geersing GJ, Harjola VP, Huisman MV, Humbert M, Jennings CS, Jiménez D, Kucher N, Lang IM, Lankeit M, Lorusso R, Mazzolai L, Meneveau N, Ní Áinle F, Prandoni P, Pruszczyk P, Righini M, Torbicki A, Van Belle E, Zamorano JL; ESC Scientific Document Group. 2019 ESC Guidelines for the diagnosis and management of acute pulmonary embolism developed in collaboration with the European Respiratory Society (ERS). Eur Heart J 2020; 41(4): 543-603

26. Tian S, Hu W, Niu L, Liu H, Xu H, Xiao SY. Pulmonary pathology of early phase 2019 novel coronavirus (COVID-19) pneumonia in two patients with lung cancer. J Thorac Oncol 2020 Feb 27. [Epub ahead of print] doi: 10.1016/j.jtho.2020.02.010

27. Xu Z, Shi L, Wang Y, Zhang J, Huang L, Zhang C, Liu S, Zhao P, Liu H, Zhu L, Tai Y, Bai C, Gao T, Song J, Xia P, Dong J, Zhao J, Wang FS. Pathological findings of COVID-19 associated with acute respiratory distress syndrome. Lancet Respir Med 2020 Feb 18. [Epub ahead of print] doi: 10.1016/S2213-2600(20)30076-X

28. Luo W,Yu H,Gou J,Li X,Sun Y,Li J,Liu L.Clinical pathology of critical patient with novel coronavirus pneumonia (COVID-19). Preprints 2020; 2020020407 https://www.preprints.org/manuscript/ 202002.0407/v4

29. Shi H, Han X, Jiang N, Cao Y, Alwalid O, Gu J, Fan Y, Zheng C. Radiological findings from 81 patients with COVID-19 pneumonia in Wuhan, China: a descriptive study. Lancet Infect Dis $2020 \mathrm{Feb}$ 24. [Epub ahead of print] doi: 10.1016/S1473-3099(20)30086-4

30. Zhao W, Zhong Z, Xie X, Yu Q, Liu J. Relation between chest CT findings and clinical conditions of coronavirus disease (COVID-19) pneumonia: a multicenter study. AJR Am J Roentgenol 2020 Mar 3. [Epub ahead of print] doi: 10.2214/AJR.20.22976

31. Koo HJ, Lim S, Choe J, Choi SH, Sung H, Do KH. Radiographic and CT features of viral pneumonia. Radiographics 2018; 38(3): 719-739

32. Franquet T, Müller NL, Giménez A, Martínez S, Madrid M, Domingo P. Infectious pulmonary nodules in immunocompromised patients: usefulness of computed tomography in predicting their etiology. J Comput Assist Tomogr 2003; 27(4): 461-468

33. Xu X, Yu C, Qu J, Zhang L, Jiang S, Huang D, Chen B, Zhang Z, Guan W, Ling Z, Jiang R, Hu T, Ding Y, Lin L, Gan Q, Luo L, Tang $X$, Liu J. Imaging and clinical features of patients with 2019 novel coronavirus SARS-CoV-2. Eur J Nucl Med Mol Imaging 2020 Feb 28. [Epub ahead of print] doi: 10.1007/s00259-020-04735-9

34. Wu J, Feng CL, Xian XY, Qiang J, Zhang J, Mao QX, Kong SF, Chen YC, Pan JP. Novel coronavirus pneumonia (COVID-19) CT distribution and sign features. Chin J Tuberc Respir Dis (Zhonghua Jie He He Hu Xi Za Zhi) 2020 Mar 3. [Epub ahead of print] (in Chinese) doi: 10.3760/cma.j.cn112147-20200217-00106

35. Falzarano D, de Wit E, Martellaro C, Callison J, Munster VJ, Feldmann H. Inhibition of novel $\beta$ coronavirus replication by a combination of interferon- $\alpha 2 b$ and ribavirin. Sci Rep 2013; 3(1): 1686

36. Momattin H, Al-Ali AY, Al-Tawfiq JA. A Systematic review of therapeutic agents for the treatment of the Middle East respiratory syndrome coronavirus (MERS-CoV). Travel Med Infect Dis 2019; 30: 9-18

37. Shi Y. What are the highlights of "Diagnosis and treatment of Disease 2019 novel coronavirus infection suitable for Military support Hubei medical team”. Chin J Tuberc Respir Dis (Zhonghua Jie He He Hu Xi Za Zhi) 2020 Feb 26. [Epub ahead of print] (in Chinese) doi: 10.3760/cma.j.cn112147-20200225-00183

38. Wang M, Cao R, Zhang L, Yang X, Liu J, Xu M, Shi Z, Hu Z, Zhong W, Xiao G. Remdesivir and chloroquine effectively inhibit the recently emerged novel coronavirus $(2019-\mathrm{nCoV})$ in vitro. Cell Res 2020; 30(3): 269-271

39. Sheahan TP, Sims AC, Graham RL, Menachery VD, Gralinski LE, Case JB, Leist SR, Pyrc K, Feng JY, Trantcheva I, Bannister R, Park Y, Babusis D, Clarke MO, Mackman RL, Spahn JE, Palmiotti CA, Siegel D, Ray AS, Cihlar T, Jordan R, Denison MR, Baric RS. Broad-spectrum antiviral GS-5734 inhibits both epidemic and zoonotic coronaviruses. Sci Transl Med 2017; 9(396): eaal3653

40. de Wit E, Feldmann F, Cronin J, Jordan R, Okumura A, Thomas T, Scott D, Cihlar T, Feldmann H. Prophylactic and therapeutic remdesivir (GS-5734) treatment in the rhesus macaque model of MERS-CoV infection. Proc Natl Acad Sci USA 2020 Feb 13. [Epub ahead of print] doi: 10.1073/pnas.1922083117

41. Chow EJ, Doyle JD, Uyeki TM. Influenza virus-related critical illness: prevention, diagnosis, treatment. Crit Care 2019; 23(1): 214

42. Shi Y, Huang Y, Zhang TT, Cao B, Wang H, Zhuo C, Ye F, Su X, Fan H, Xu JF, Zhang J, Lai GX, She DY, Zhang XY, He B, He LX, Liu YN, Qu JM. Chinese guidelines for the diagnosis and treatment of hospital-acquired pneumonia and ventilator-associated pneumonia in adults (2018 Edition). J Thorac Dis 2019; 11(6): 2581-2616

43. Nishida O, Ogura H, Egi M, Fujishima S, Hayashi Y, Iba T, Imaizumi H, Inoue S, Kakihana Y, Kotani J, Kushimoto S, Masuda Y, Matsuda N, Matsushima A, Nakada TA, Nakagawa S, Nunomiya S, Sadahiro T, Shime N, Yatabe T, Hara Y, Hayashida K, Kondo Y, Sumi Y, Yasuda H, Aoyama K, Azuhata T, Doi K, Doi M, Fujimura N, Fuke R, Fukuda T, Goto K, Hasegawa R, Hashimoto S, Hatakeyama J, Hayakawa M, Hifumi T, Higashibeppu N, Hirai K, Hirose T, Ide K, Kaizuka Y, Kan'o T, Kawasaki T, Kuroda H, Matsuda A, Matsumoto S, Nagae M, Onodera M, Ohnuma T, Oshima K, Saito N, Sakamoto S, Sakuraya M, Sasano M, Sato N, Sawamura A, Shimizu K, Shirai K, Takei T, Takeuchi M, Takimoto $\mathrm{K}$, Taniguchi T, Tatsumi H, Tsuruta R, Yama N, Yamakawa K, Yamashita C, Yamashita K, Yoshida T, Tanaka H, Oda S. The Japanese Clinical Practice Guidelines for Management of Sepsis and Septic Shock 2016 (J-SSCG 2016). Acute Med Surg 2018; 5(1): 3 89

44. Lee HY, Rhee CK, Lee JW. Feasibility of high-flow nasal cannula oxygen therapy for acute respiratory failure in patients with hematologic malignancies: a retrospective single-center study. J Crit Care 2015; 30(4): 773-777

45. Dangers L, Montlahuc C, Kouatchet A, Jaber S, Meziani F, Perbet S, Similowski T, Resche-Rigon M, Azoulay E, Demoule A; REVA Network (Research Network in Mechanical Ventilation) and the Groupe de Recherche en Réanimation Respiratoire en OncoHématologie (GrrrOH); List of contributors who included study patients: Angers University Hospital, Angers, France. Dyspnoea in patients receiving noninvasive ventilation for acute respiratory failure: prevalence, risk factors and prognostic impact: a prospective observational study. Eur Respir J 2018; 52(2): 1702637

46. Fan E, Del Sorbo L, Goligher EC, Hodgson CL, Munshi L, Walkey AJ, Adhikari NKJ, Amato MBP, Branson R, Brower RG, Ferguson ND, Gajic O, Gattinoni L, Hess D, Mancebo J, Meade MO, 
McAuley DF, Pesenti A, Ranieri VM, Rubenfeld GD, Rubin E, Seckel M, Slutsky AS, Talmor D, Thompson BT, Wunsch H, Uleryk E, Brozek J, Brochard LJ; American Thoracic Society, European Society of Intensive Care Medicine, and Society of Critical Care Medicine. An Official American Thoracic Society/European Society of Intensive Care Medicine/Society of Critical Care Medicine Clinical Practice Guideline: Mechanical Ventilation in Adult Patients with Acute Respiratory Distress Syndrome. Am J Respir Crit Care Med 2017; 195(9): 1253-1263

47. Fan E, Brodie D, Slutsky AS. Diagnosis and treatment in acute respiratory distress syndrome-reply. JAMA 2018; 320(3): 306

48. Yang HH, Zhou Y. Effect of invasive and non-invasive positive pressure ventilation on plasma brain natriuretic peptide in patients with chronic obstructive pulmonary disease and severe respiratory failure. J South Med Univ (Nan Fang Yi Ke Da Xue Xue Bao) 2010; 30(10): 2377-2379 (in Chinese)

49. Hui DS. Severe acute respiratory syndrome (SARS): lessons learnt in Hong Kong. J Thorac Dis 2013; 5(Suppl 2): S122-S126

50. Ronco C, Navalesi P, Vincent JL. Coronavirus epidemic: preparing for extracorporeal organ support in intensive care. Lancet Respir Med 2020; 8(3): 240-241

51. Cheng Y, Luo R, Wang K, Zhang M, Wang Z, Dong L, Li J, Yao Y, Ge S, Xu G. Kidney impairment is associated with in-hospital death of COVID-19 patients. Medrxiv 2020; doi: 10.1101/ 2020.02.18.20023242

52. Träger K, Schütz C, Fischer G, Schröder J, Skrabal C, Liebold A, Reinelt H. Cytokine reduction in the setting of an ARDS-associated inflammatory response with multiple organ failure. Case Rep Crit Care 2016; 2016: 9852073

53. Mair-Jenkins J, Saavedra-Campos M, Baillie JK, Cleary P, Khaw FM, Lim WS, Makki S, Rooney KD, Nguyen-Van-Tam JS, Beck CR; Convalescent Plasma Study Group. The effectiveness of convalescent plasma and hyperimmune immunoglobulin for the treatment of severe acute respiratory infections of viral etiology: a systematic review and exploratory meta-analysis. J Infect Dis 2015; 211(1): 80-90

54. Stockman LJ, Bellamy R, Garner P. SARS: systematic review of treatment effects. PLoS Med 2006; 3(9): e343

55. Mustafa S, Balkhy H, Gabere MN. Current treatment options and the role of peptides as potential therapeutic components for Middle East respiratory syndrome (MERS): a review. J Infect Public Health 2018; 11(1): 9-17

56. Lee PI, Hsueh PR. Emerging threats from zoonotic coronavirusesfrom SARS and MERS to 2019-nCoV. J Microbiol Immunol Infect $2020 \mathrm{Feb}$ 4. [Epub ahead of print] doi: 10.1016/j.jmii.2020.02.001

57. Chen L, Xiong J, Bao L, Shi Y. Convalescent plasma as a potential therapy for COVID-19. Lancet Infect Dis 2020 Feb 27. [Epub ahead of print] doi: 10.1016/S1473-3099(20)30141-9

58. Kaneko Y, Kato M, Tanaka Y, Inoo M, Kobayashi-Haraoka H, Amano K, Miyata M, Murakawa Y, Yasuoka H, Hirata S, Tanaka E, Miyasaka N, Yamanaka H, Yamamoto K, Takeuchi T; SURPRISE study group. Tocilizumab discontinuation after attaining remission in patients with rheumatoid arthritis who were treated with tocilizumab alone or in combination with methotrexate: results from a prospective randomised controlled study (the second year of the SURPRISE study). Ann Rheum Dis 2018; 77(9): 1268-1275

59. Kaneko Y, Kameda H, Ikeda K, Ishii T, Murakami K, Takamatsu H, Tanaka Y, Abe T, Takeuchi T. Tocilizumab in patients with adultonset still's disease refractory to glucocorticoid treatment: a randomised, double-blind, placebo-controlled phase III trial. Ann Rheum Dis 2018; 77(12): 1720-1729

60. Stone JH, Tuckwell K, Dimonaco S, Klearman M, Aringer M, Blockmans D, Brouwer E, Cid MC, Dasgupta B, Rech J, Salvarani C, Schett G, Schulze-Koops H, Spiera R, Unizony SH, Collinson N. Trial of tocilizumab in giant-cell arteritis. N Engl J Med 2017; 377 (4): 317-328 